\title{
Note
}

\section{Duckling mortality at a river weir}

\author{
SteWART B. Rood ${ }^{1, *}$ and Amber Willcocks ${ }^{1}$ \\ ${ }^{1}$ Department of Biological Sciences, University of Lethbridge, Lethbridge, Alberta T1K 3M4 Canada \\ *Corresponding author: rood@uleth.ca
}

Rood, S.B., and A. Willcocks. 2019. Duckling mortality at a river weir. Canadian Field-Naturalist 133(2): 167-171. https:// doi.org/10.22621/cfn.v133i2.2159

\begin{abstract}
River weirs are low-head dams that dissipate energy by creating hydraulic recirculation zones at their base. These recirculation zones are a major cause of human drownings and have been referred to as "drowning machines". We observed an event that allowed us to add ducklings to the list of weir victims. As a Mallard (Anas platyrhynchos) hen and her brood floated over the Calgary weir, the mother flew safely over the hydraulic recirculation. The ducklings drifted into the recirculation and three quickly passed through; four were stalled, repeatedly recirculated, and died. We observed other regional weirs where adult birds commonly flew over the hazard. We did not observe any other waterfowl drifting into recirculation zones, and we found no prior report of this lethal hazard. Although mortality might be rare at each weir, with hundreds of thousands of low-head dams worldwide, the collective hazard could be substantial. Weirs can be designed to eliminate the lethal recirculation zone, and the apparent hazard to ducklings could provide another motivation to redesign or modify these common structures.
\end{abstract}

Key words: Bow River; dams; mortality; waterfowl

Human developments impose many lethal challenges on wildlife. Avian mortality can follow collisions with windows, towers, power lines, airplanes, or wind turbines (Weir 1976; Avery et al. 1980). Alterations to streams, ponds, and lakes impose additional challenges for waterfowl, including the flooding of nests and increased predator access (Mauser $e t$ al. 1994; Flint and Grant 1997). We are investigating the ecological consequences of weirs and other river dams (Rood et al. 2003, 2010) and observed another, apparently unreported, cause of waterfowl mortality.

Our observation was from the viewing platform at the weir across the Bow River in Calgary, Canada (Figure $1 ; 51^{\circ} 2.61^{\prime} \mathrm{N}, 114^{\circ} 0.85^{\prime} \mathrm{W}$ ). This weir creates an elevated head pond upstream, which allows for offstream water diversion for irrigation. The concrete weir produces a drop of about $2 \mathrm{~m}$ into the stilling pool, forming a hydraulic recirculation zone, which is also referred to as a "hydraulic jump" or "hole" (Figure 2; Makuk 1988; Bradshaw 2004). This recirculation zone dissipates energy to reduce erosion of the weir base and downstream channel. Because of the recirculation, buoyant objects that float over the sill are often stalled in the trough, and are retained there or plunge down into the seam created by falling water. These objects flow slightly downstream, then resurface because of their buoyancy while still within the turbulent recirculation zone. This imposes a repetitive and somewhat violent cycle, and the recirculation zone can thus be retentive, as revealed with sticks, logs, and a wheel in the trough of the Calgary weir (Figures 1 and 3).

With the hydraulic recirculation, low-head dams will often stop swimmers or stall and capsize small boats, and then recirculate the victims. The lethal hazard of these "drowning machines" is well recognized, as human drownings at river weirs continue to represent about a fifth of recent North American river fatalities (Walbridge 2000; Bradshaw 2004). The Calgary weir has been especially lethal, with at least 10 fatalities from 1982 through 2007, including four double drownings (Makuk 1988; Canadian River Safety 2019). Largely because of the drowning hazard, this weir was modified in about 2010 to divide the single major drop into a sequence of smaller irregular drops, eliminating the retentive hydraulic recirculation zone and creating the safer Harvie Passage paddling park.

While at that construction site on 4 June 2009, we observed a fatal wildlife incident. Near mid-day, a 


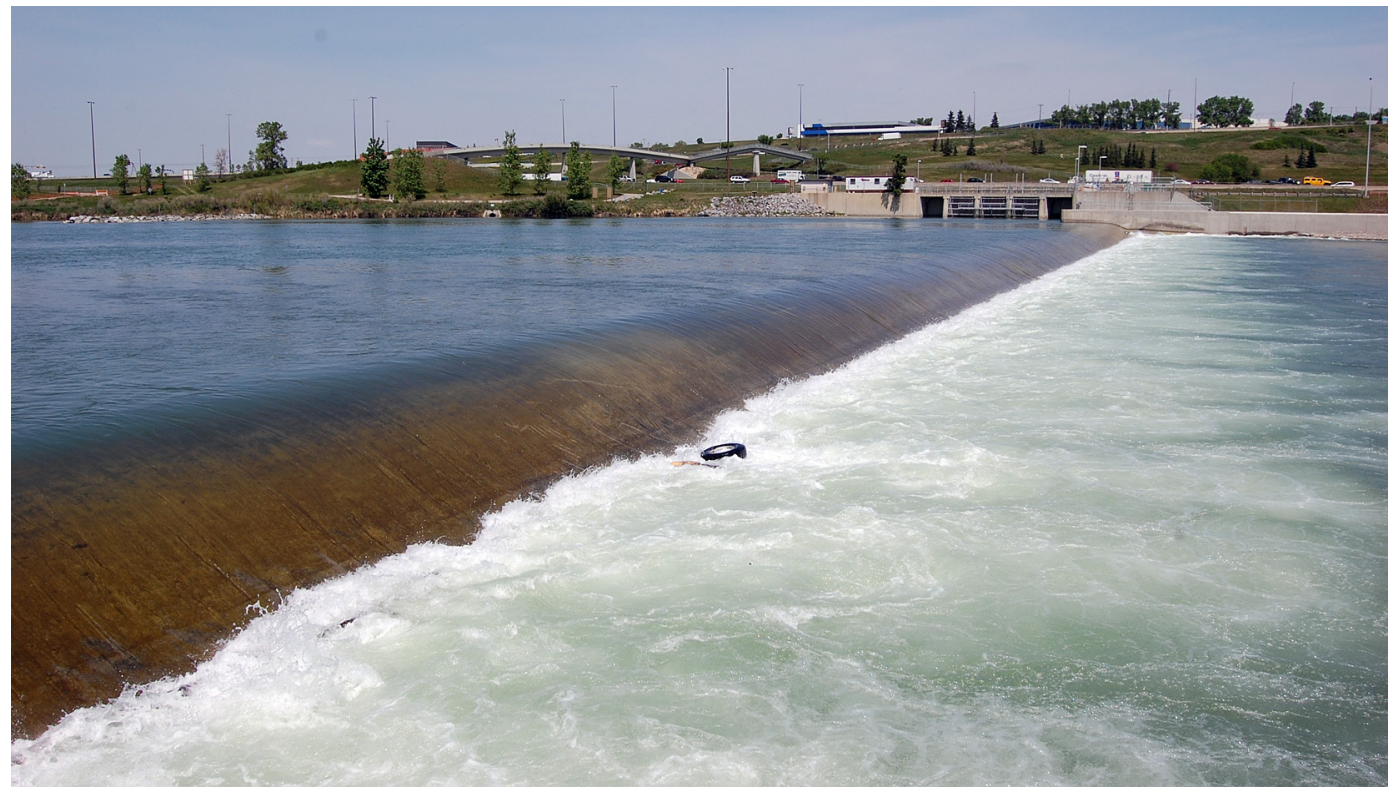

Figure 1. The Calgary weir in June 2009 (discharge $109 \mathrm{~m}^{3} / \mathrm{s}$ ), displaying the river water flowing over the weir and into the hazardous hydraulic recirculation zone, with trapped sticks and a wheel. The structure on the far side allows offstream diversion into an irrigation canal. This system was subsequently modified with the Harvie Passage to produce safer paddling channels. Photo: Stewart Rood.

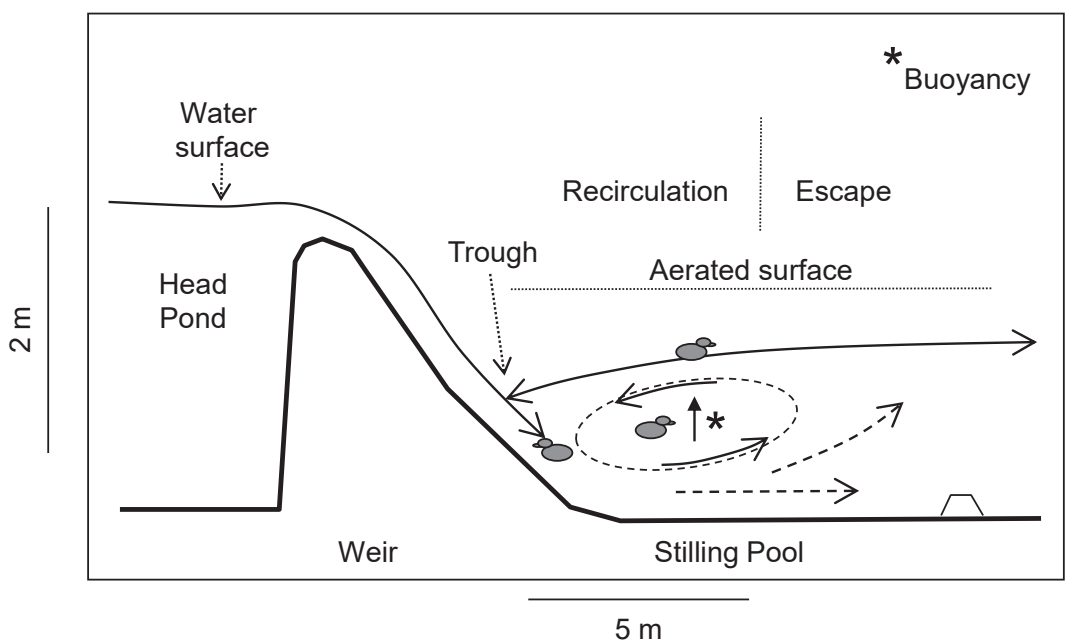

Figure 2. A cross-section of the Calgary weir and hydraulic recirculation zone with scaling based on Makuk (1988) and Golder (2002). The positions of the submerged ducklings are based on flume simulations with objects of similar buoyancy and observed emergence patterns. Note the exaggerated vertical scale.

Mallard (Anas platyrhynchos) hen and her brood of seven ducklings drifted slowly along the south bank (Figure 3). As water flowed over the weir, the ducklings turned upstream and appeared to paddle vigorously. As the hen floated over the sill, she rose with a few wing strokes and glided downstream beyond the recirculation zone. Some of the ducklings turned toward her and paddled vigorously downstream.
Paddling into the trough, three passed through fairly quickly, apparently aided by a break in the recirculation because of a tumbling log in the trough. The other four ducklings were stalled. Each was plunged down, and we observed three of the four resurface a few seconds later in the aerated surface, 3-4 m downstream. Despite paddling downstream, each was drawn back upstream into the trough and 


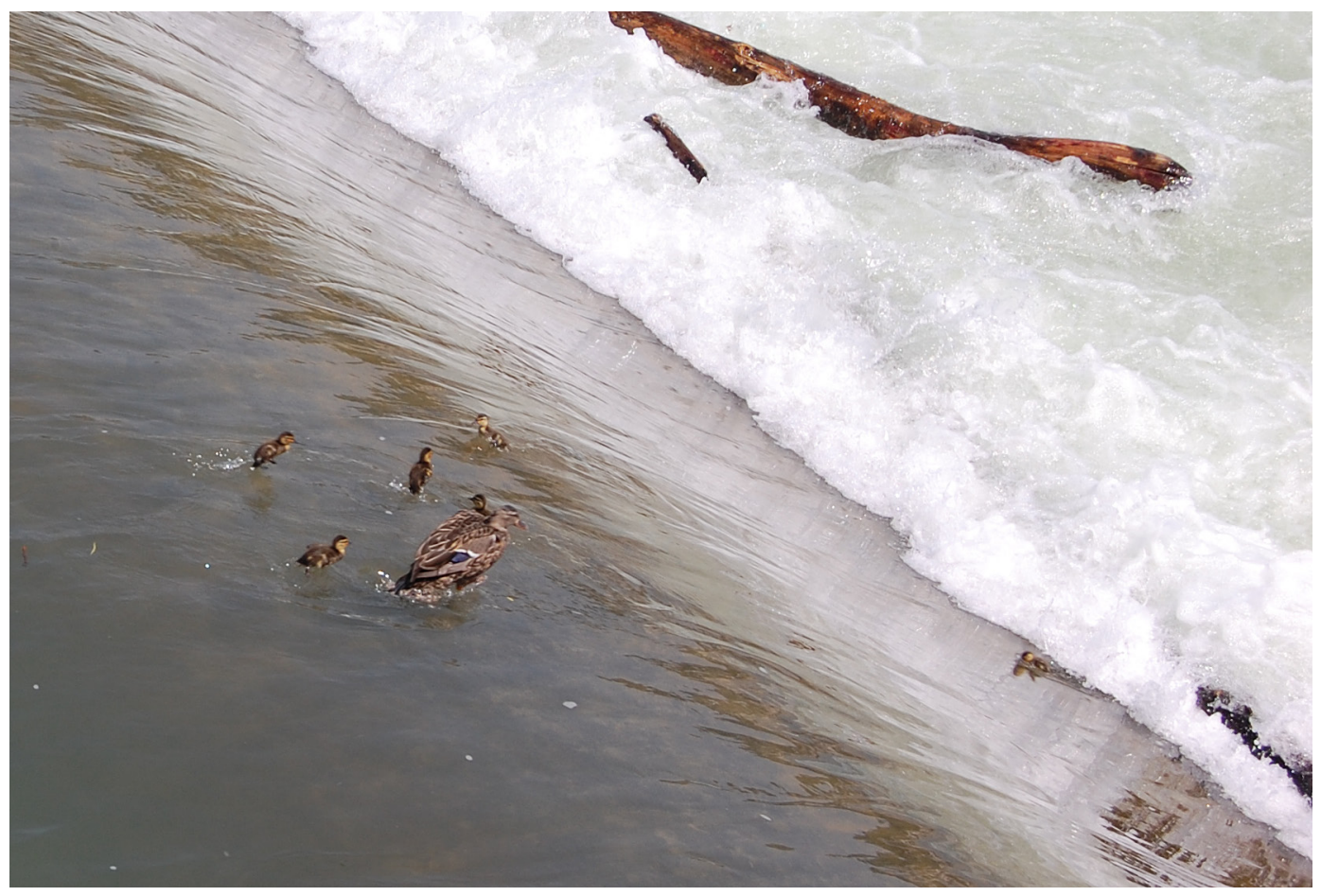

FIGURE 3. A Mallard (Anas platyrhynchos) hen with seven ducklings approaching the hydraulic recirculation zone at the Calgary weir, 4 June 2009. Three of these ducklings survived, while four died. The hen is just rising and subsequently flew over the recirculation area. Photo: Stewart Rood.

again plunged under water. With each recirculation, the ducklings appeared to be weakened as they became less vigorous. We observed two ducklings recirculating three times and one four times, but did not observe the fourth over the next few minutes. After about five more minutes, one duckling emerging in the water downstream from the hydraulic recirculation area, drifting passively on its side, apparently dead. We observed no further evidence of the remaining three ducklings over an additional $30 \mathrm{~min}$.

This incident demonstrates that a low-head dam can be lethal for ducklings. The mature hen was readily able to fly over the retentive hydraulic recirculation zone, but the ducklings were unable to fly and were, therefore, vulnerable. Of the seven ducklings, four apparently died, indicating that this powerful recirculation was quite hazardous.

This physical hazard from low-head dams may be very common; the design of these dams is fairly universal and consistently produces retentive and lethal hydraulic recirculation zones (Makuk 1988; Walbridge 2000; Bradshaw 2004). There are about 45 000 large dams world-wide (World Commission on Dams 2000) and low-head dams are probably about ten-fold more numerous (Chandler and Chapman 2003; Doyle et al. 2003). With this widespread occur- rence and the apparent lethality for ducklings, we conclude that weirs could provide a substantial hazard for juvenile waterfowl.

To investigate whether this hazard is recognized in the field of ecology, we conducted Google Scholar and Web of Science literature searches with search term combinations including duck, duckling, mortality, death, hazard, dam, and weir. These revealed extensive reports on duckling mortality, including reviews and bibliographies, showing that duckling mortality is considerable (Ringleman and Longcore 1982; Savard et al. 1991; Flint and Grand 1997), largely as a result of predation (Talent et al. 1983; Mauser et al. 1994). Although many reports of hazards to waterfowl and other birds from various types of artificial structures exist (Weir 1976; Avery et al. 1980), we found no reference to the drowning hazard from river weirs. Wildlife biologists with Alberta Environment and Parks reported that they had never seen ducklings or goslings drifting over weirs, but were not surprised by the possibility, because waterfowl are abundant in head ponds above weirs in southern Alberta.

News and social media websites were another source of information. A Google search (September 2019) on "ducklings and weirs" revealed YouTube, Facebook, and news media videos, photographs, and 
reports of ducklings unable to follow the mother hen up and over weirs or stranded in troughs or drains below weirs. These ducklings were uninjured and were often assisted by observers or wildlife officers; for some repetitive cases, screens or other measures solved the stranding. We found no report of ducklings retained, injured, or killed in the hydraulic recirculation zone of a river weir.

Over five years, we visited other river weirs, including the 1-m-high Lethbridge Northern Irrigation District weir $\left(49^{\circ} 39.9^{\prime} \mathrm{N}, 113^{\circ} 36.1^{\prime} \mathrm{W}\right)$, the $1.5-\mathrm{m}$ City of Lethbridge weir on the Oldman River $\left(49^{\circ} 40.9^{\prime} \mathrm{N}\right.$, $\left.112^{\circ} 51.4^{\prime} \mathrm{W}\right)$, and the $3-\mathrm{m}$ Carseland weir on the Bow River $\left(50^{\circ} 49.5^{\prime} \mathrm{N}, 113^{\circ} 26.6^{\prime} \mathrm{W}\right)$. These weirs also produce retentive hydraulic recirculation zones and humans have drowned at the Lethbridge and Carseland weirs (Canadian River Safety 2019). We undertook 50, 6-hour observer-days at these three weirs during June from 2010 through 2015.

During these observations, water birds were common near each of the weirs, including the piscivorous American White Pelican (Pelecanus erythrorhynchos) and Double-crested Cormorant (Phalarocorax auritus). In addition to Mallards, other ducks were abundant, including Common Merganser (Mergus merganser), Common Goldeneye (Bucephala clangula), occasional Wood Ducks (Aix sponsa), and other species. Canada Goose (Branta canadensis), including goslings, were also abundant, along with Ringbilled (Larus delawarensis) and other gulls. We commonly observed adults drifting toward the weirs, and they would consistently fly before drifting into the hydraulic recirculation zone. Ducklings or goslings were common, but we did not see any others drift over the weirs; thus, it is probably uncommon for waterfowl to drift into recirculation zones. We have repeatedly observed pelicans and some other birds fishing right below and even in the recirculation zone during summer intervals when river flows are lower and the hydraulic power and hazard are probably slight (Figure 4).

Following these observations, we suspect that the hazard to waterfowl varies considerably across weirs and with different river flows. A small weir on a small stream would produce a modest hydraulic recirculation zone that would be less capable of stopping and recirculating ducklings. The hydraulic force and hazard would increase with increasing drop height and stream discharge. The Carseland weir hydraulic system was very loud and this may have signaled its presence from $100 \mathrm{~m}$ or more upstream. Waterfowl were abundant in the upstream pond, but remained well away from that drop. With the reduced hazard of smaller weirs and noise cues of larger weirs,

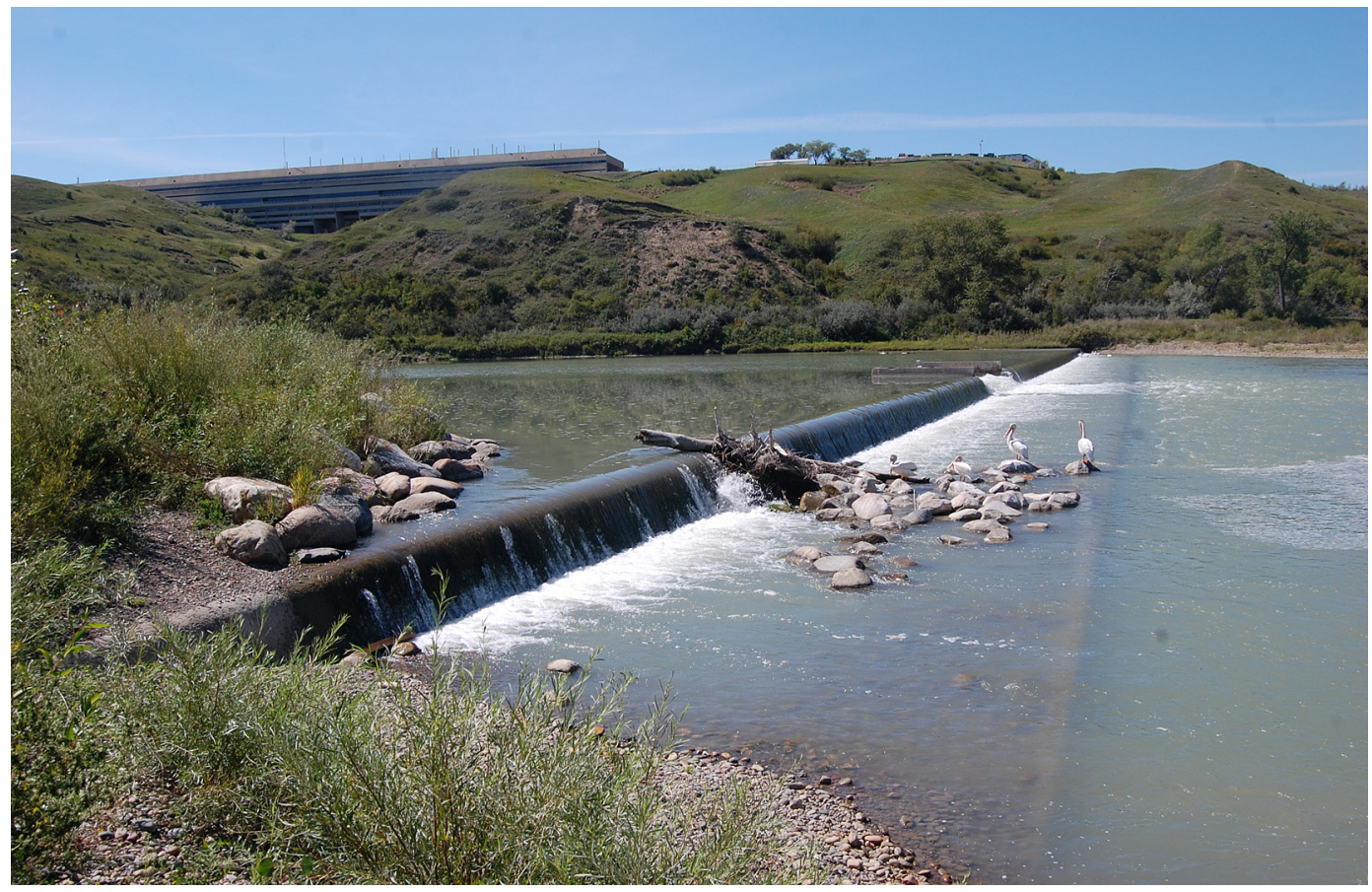

FIgURE 4. The Lethbridge weir across the Oldman River in late summer when flows are low and the recirculation hazard is reduced. American White Pelicans (Pelecanus erythrorhynchos) are common, feeding on fish that are blocked by the weir from upstream passage. Photo: Stewart Rood. 
it is possible that intermediate-sized weirs, such as the Calgary weir, might provide the greatest risk to ducklings.

The lack of prior reporting of duckling deaths in weir recirculation zones could indicate that this source of mortality is rare. Conversely, the lack of evidence may reflect ducklings' inconspicuous nature. Ducklings are small and cryptic, and hens encourage secretive behaviour (Mauser et al. 1994). Also, reducing the likelihood of observation, humans are discouraged from approaching river weirs by signage or fencing. Although stilling pools, the slow flowing zones downstream of weirs, are sometimes favoured for fishing, this is less common during the interval of turbid water and high flow rates in late spring and early summer, when ducklings are unable to fly and thus more vulnerable.

Although the extent of mortality is unknown, the prospective drowning hazard to waterfowl could provide one more reason to avoid weir designs that create "drowning machines". In addition, modifications to existing weirs to eliminate the hydraulic recirculation zone should reduce the risk for ducklings and possibly other wildlife, as well as humans. For example, the modifications to the Calgary weir to create the safer Harvie Passage might reduce future duckling mortality at this location where we observed the tragic drownings in 2009.

\section{Acknowledgements}

This work was supported by funding from Alberta Innovates and Alberta Environment and Parks (AEP). We extend thanks to ornithologist Andrew Hurly (University of Lethbridge) and ecohydrologist Andrew Paul (AEP) for valuable inputs and editors Dwayne Lepitzki and William Halliday and two reviewers for many helpful recommendations.

\section{Literature Cited}

Avery, M.L., P.F. Springer, and N.S. Dailey. 1980. Avian mortality at man-made structures: an annotated bibliography (revised). United States Fish and Wildlife Service, Department of the Interior, Washington, DC, USA. FWS/OBS-80/54.

Bradshaw, S. 2004. River Safety: A Floater's Guide. Lyons Press, Guilford, Connecticut, USA.

Canadian River Safety. 2019. Map of incidents in Alberta. Canadian River Safety Project, Canada. Accessed September 2019. http://www.canadianriversafety.ca/w/core/ index.php?title=Province:Alberta.

Chandler, J.A., and D. Chapman. 2003. Existing habitat conditions of tributaries formerly used by anadromous fish (appendix 2.1-2). Technical report FERC no. 1971. Idaho Power Company, Boise, Idaho, USA.

Doyle, M.W., E.H. Stanley, and J.M. Harbor. 2003. Channel adjustments following two dam removals in Wisconsin. Water Resources Research 39: 1011. https:// doi.org/10.1029/2002WR001714

Flint, P.L., and J.B. Grand. 1997. Survival of spectacled eider adult females and ducklings during brood rearing. Journal of Wildlife Management 61: 217-221. https:// doi.org/10.2307/3802430

Golder Associates. 2002. Pre-design of the preferred alternatives to modify the Western headworks weir in Calgary. Golder Associates Ltd., Calgary, Alberta, Canada.

Makuk, J.S. 1988. Multiple use of water resources: adapting weirs for recreation. M.Env. Design thesis, University of Calgary, Calgary, Alberta, Canada.

Mauser, D.M., R.L. Jarvis, and D.S. Gilmer. 1994. Survival of radio-marked mallard ducklings in northeastern California. Journal of Wildlife Management 58: 8287. https://doi.org/10.2307/3809552

Ringleman, J.K., and J.R. Longcore. 1982. Survival of black ducks during brood rearing. Journal of Wildlife Management 46: 622-628. https://doi.org/10.2307/ 3808552

Rood, S.B., J.H. Braatne, and L.A. Goater. 2010. Favorable fragmentation: river reservoirs can impede downstream expansion of riparian weeds. Ecological Applications 20: 1664-1677. https://doi.org/10.1890/09-0063.1

Rood, S.B., C.R. Gourley, E.M. Ammon, L.G. Heki, J.R. Klotz, M.L. Morrison, D. Mosely, G.G. Scoppettone, S. Swanson, and P.L. Wagner. 2003. Flows for floodplain forests: a successful riparian restoration. BioScience 53: 647-656. http://doi.org/c4tvrc

Savard, J.-P.L., G.E.J. Smith, and J.N.M. Smith. 1991. Duckling mortality in Barrow's Goldeneye and Bufflehead broods. Auk 108: 568-577. https://doi.org/10.2307/ 4088097

Talent, L.G., R.L. Jarvis, and G.L. Krapu. 1983. Survival of mallard broods in south-central North Dakota. Condor 85: 74-78. https://doi.org/10.2307/1367893

Walbridge, C. 2000. The American Canoe Association's River Safety Report 1996-1999 (Second Edition). Menasha Ridge Press, Birmingham, Alabama, USA.

Weir, R.D. 1976. Annotated bibliography of bird kills at man-made obstacles: a review of the state of the art and solutions. Department of Fisheries and the Environment, Canadian Wildlife Service, Ottawa, Ontario, Canada.

World Commission on Dams. 2000. Dams and Development: a New Framework for Decision-making. Earthscan Publications Ltd., London, United Kingdom.

Received 22 November 2018

Accepted 17 October 2019 